\title{
Diseño urbano y sentido de lugar: análisis de lugares con sentido, el caso de estudio de Valdivia.
}

Urban design and the sense of place: analysis of meaningful places in Valdivia.

Laura Yazmin Rodríguez Negrete, Ernesto Antonio Zumelzu Scheel

\section{Filiación}

Universidad Austral de Chile

E mail: Irodrigueztitulo@gmail.com - antoniozumelzu.arq@gmail.com

Primera versión recibida en: 15 de marzo de 2014

Última versión recibida en: 15 de junio de 2014

\section{Resumen}

Las ciudades chilenas debieran ser motivo de profunda preocupación, ya que en ellas se concentra no solo el grueso de la población, sino también un creciente descontento. Las graves frustraciones a consecuencia de conflictos asociados a la funcionalidad, como también a problemas de la pérdida de lazos de pertenencia con el espacio urbano, los hace habitar ciudades sin sentido.

Abordar lo expuesto por supuesto invita no solo a pensar el espacio urbano funcional, sino también desde la subjetividad de sus habitantes. Los lugares se pueden volver fuente que dota de sentido a la vida urbana al transformarse en lugares icónicos, entonces comprender el sentido que guardan los lugares para los individuos es fundamental.

Por otro lado, los principios orientadores del diseño urbano definen ciertas características de los lugares considerados óptimos y la literatura si bien no es extensa, orienta al respecto. Sin embargo la vinculación entre la teoría del diseño urbano, los lugares con sentido y las propuestas que aborden lo anterior no ha sido elaborada aun.

Este artículo tiene por objetivo aplicar la teoría integradora del diseño urbano propuesta por Sternberg (2000) enfatizando el sentido del lugar mediante diversos proyectos académicos desarrollados en el Taller de Urbanismo de la Escuela de Arquitectura, UACH. El trabajo muestra la aplicación de dichos principios en un proyecto en la ciudad de Valdivia. Los resultados se enfocan en propuestas de reconversión espacial urbana de los lugares identificados, apuntando al desarrollo de una metodología que integre la teoría y la práctica.

\section{Palabras claves}

Diseño urbano; lugar, Valdivia; espacio público.

\begin{abstract}
Chilean cities should be subject of serious concern, not only because population in them is growing in size, but also in discontent. Functionality related problems, as well as a loss of local identity, make dwelling in urban areas meaningless.

Addressing the aforementioned problems requires an approach that not only considers functionality, but also perceptual and subjective issues that arise from the perception that the inhabitants of cities have, in relation with their environment. Therefore, the sense of place appears to be a fundamental aspect to look at, since it can transform the way of inhabiting a certain area.

Moreover, some guidance regarding what is a good place, and should it be can be found within the principles of urban design. However, the linkage between design theory, creating sense of place and the urban design practice, have not been developed yet.

This articles intends to look at how Sternberg's integrative urban design theory could be applied, putting emphasis on the production of places with meaning, through the projects
\end{abstract}




\section{REVISTA DE \\ URBANISMO}

ISSN 0717-5051

http://revistaurbanismo.uchile.cl
Revista de Urbanismo N³0 - Enero - Junio de 2014 Departamento de Urbanismo - FAU - Universidad de Chile

developed in an architecture studio at the Universidad Austral de Chile, for the city of Valdivia. The results focus on the spatial transformation of key areas of the city, through a methodology that integrates theory and practice.

\section{Key words}

Urban design; place; Valdivia; public space.

\section{Sumario}

Introducción

1 De la teoría del sentido a la teoría del diseño urbano

2 Metodología.

3 Resultados.

Conclusiones

Bibliografía

\section{Introducción}

Las ciudades chilenas, De acuerdo a datos del INE 2002, amparan a más del $86 \%$ de los habitantes del país, sin embargo los ciudadanos manifiestan una gran insatisfacción al habitarlas. Ese descontento desemboca en el aumento en los niveles de conflictividad urbana, donde los habitantes expresan las graves frustraciones de problemas asociados a la funcionalidad, pero también a problemas de la perdida de lazos de pertenencia con el espacio circundante $^{1}$. Situación mencionada también en otros contextos geográficos ${ }^{2}$. Habitan ciudades sin sentido.

Solucionar lo anterior requiere reflexionar acerca del espacio urbano desde posturas no solo funcionalistas, sino desde el mundo subjetivo de las vivencias ${ }^{3}$. Donde la recuperación del sentido de vivir en comunidad, fortalezca los lazos de pertenencia al dar cuenta de una identidad como reserva de memorias, pero también como proyecto en constante desarrollo.

Mejores ciudades son ciudades que albergan múltiples lugares con sentido, sentidos que son persistentes en el tiempo, pero también sentidos que se renuevan, fortaleciendo el sentido de pertenencia de sus habitantes, quienes perciben en la conformación urbana una articulación profunda con su propia identidad colectiva cultural4.

En éste sentido, el lugar tiene un importante papel que cumplir. Los lugares se pueden volver fuente que dota de sentido a la vida urbana, transformándose en lugares icónicos para la comunidad, observándose una fuerte vinculación entre los lugares icónicos y la identidad de la ciudad, sea este un aspecto positivo, re-afirmante de la vida o negativo, fuente de conflictos, como lo señala Picón ${ }^{5}$. Lugares que le den sostén a la existencia son necesarios y a pesar de lo anterior ellos no han sido examinados a la luz de un marco teórico transdisciplinario que ofrezca soluciones, que si bien podrían no ser definitivas, al menos entregan esquemas orientadores permitiendo una discusión más innovadora y fecunda.

1 (Márquez, 2006)

2 (Inam: 2011)

3 (Munizaga: 1997)

4 (Rodríguez: 2012)

5 Picón (2008) 
Los principios orientadores del diseño urbano, por otra parte, definen ciertas características de los lugares considerados óptimos y la literatura si bien no es extensa, recomienda al respecto. Sin embargo la vinculación entre la teoría del diseño urbano, los lugares con sentido y la identidad de las ciudades es un aspecto aun no elaborado en la diversidad y profundidad que amerita ${ }^{6}$.

Este artículo tiene por objetivo aplicar la teoría integradora del diseño urbano propuesta por Sternberg7, enfatizando el sentido del lugar mediante diversos proyectos académicos desarrollados en el Taller de Urbanismo de la carrera de arquitectura de la Universidad Austral de Chile. El trabajo muestra la aplicación de dichos principios, utilizando la ciudad de Valdivia como caso de estudio. Los resultados se enfocan en propuestas de reconversión espacial urbana de los lugares con sentido identificados previamente, apuntando al desarrollo de una metodología que integre la teoría urbana transdisciplinaria y la práctica proyectual.

\section{De la teoría del sentido a la teoría del diseño urbano}

Para muchos habitantes, la ciudad es, sin lugar a dudas, una fuente icónica del sentido, por lo que, según Holzapfel, "Las señaladas fuentes icónicas son los significantes y símbolos del sentido, y lo interesante es como revelan la cualidad del sentido de entificarse, sustancializarse"8. El filósofo, define teoréticamente la existencia de fuentes dispensadoras que le dan sentido a la existencia, dentro de las cuales estarían; las referenciales de carácter universal, tales como: el amor, la creatividad, la muerte, la familia, el trabajo, el juego, el poder. Las programáticas, de carácter histórico, tales como: la religión, la ciencia, la política, la filosofía, la economía, la historia. Pero también están las ocasionales, donde el sentido

Se genera a partir de, precisamente, ocasiones, momentos, oportunidades pasajeras y azarosas, como la ocasión de estar de paseo o de viaje con un grupo con el cual compartimos distintas experiencias; la ocasión de ver una película o de leer un libro. Resulta imposible clasificar las fuentes ocasionales de sentido. Ellas están en perpetua variedad y mutabilidad, y son individuales, lo que las diferencia de las fuentes referenciales o programáticas que son, antes bien, en extremo fijas y además de carácter social, histórico o incluso propias de toda la humanidad. ${ }^{9}$

De acuerdo a lo anterior, el vínculo de las fuentes ocasionales con el espacio, -que aun siendo individuales- pueden estar contenidas en determinados lugares de la ciudad, de acuerdo a Rodríguez $^{10}$ mayoritariamente en el espacio más público, y en virtud de ésta condición potencial, claramente pueden convertirse en fuentes persistentes de sentido. En conclusión, es en ésta condición donde radica la relevancia del diálogo respecto de las fuentes ocasionales de sentido; portadoras de renovación individual y potencialmente factibles de reiterarse, hasta convertirse en una fuente persistente que dota de sentido a quienes habitan la ciudad. $Y$, como hemos visto, dado que esas fuentes ocasionales son susceptibles de convertirse en persistentes, debido a los lazos que contraemos con ellas, en términos de compromiso y dedicación, también ellas están determinadas por las fuentes referenciales. Por su condición material, participan de esta determinación también las fuentes icónicas.

Si ciertos objetos, lugares, paisajes, como el anillo, un río, una catedral y hasta nuestro computador se constituyen en dispensadores de sentido, ello se explica porque en alguna forma todo aquello está en conexión con las fuentes referenciales.

6 (Talen: 2011)

7 Sternberg (2000)

8 Holzapfel (2005)

9 (Holzapfel, 2005)

10 Rodríguez (2012) 
Apreciamos cosas, lugares, obras arquitectónicas, paisajes, porque suscitan en nosotros un sentir erótico o lúdico, como también en función del saber y la erudición. ${ }^{11}$

Aun cuando el autor ${ }^{12}$ establece que "con las fuentes icónicas ocurre algo similar que con las fuentes ocasionales: su clasificación es imposible; tan solo se puede dar ejemplos", examinar su ligazón con las fuentes referenciales, es la clave explicativa respecto de su capacidad de dotar de sentido a los lugares de la ciudad, materia que ha sido abordada, en un lenguaje distinto, por teóricos del diseño urbano ${ }^{13}$.

En virtud de la discusión anterior, quisiéramos abrir la posibilidad a una ampliación de la teoría del sentido. Sin pretender elaborar una filosofía del espacio, existen aspectos en los cuales una aproximación teórica geográfica urbana podría resultar sugerente al problematizar la relación entre sentido y lugar, materia de alto interés para la geografía contemporánea y que ha sido ampliamente problematizada.

Muchos geógrafos de esta manera usan "lugar" en este sentido específico, para referirse a la significancia de lugares particulares para las personas. Estos sentimientos por el "lugar" no son vistos como triviales; los geógrafos argumentan que los sentidos del lugar se desarrollan desde cada aspecto de la experiencia vital de los individuos y estos sentidos invaden la vida y la experiencia cotidiana. ${ }^{14}$

"El lugar es un concepto central en la geografía humana en general y en particular en la geografía cultural"15, y siendo un concepto entendido por la mayoría de los geógrafos como un "estado incesante de convertirse", es distinguido por su significado subjetivo y en la manera en la cual es construido y diferenciado. En este sentido la contribución a la discusión, con ésta investigación, se ve refrendada por Cuthbert, para quien "es un debate pendiente la manera en que, en el medio ambiente construido, el significado es "producido, consumido, circulado e intercambiado, tal como es distorsionado, disfrazado, transformado o suprimido..."16.

La ciudad al ser explorada como una fuente icónica del sentido, surge desde ser un ente concreto, significante de las fuentes dispensadoras de sentido. "Desde una perspectiva místicapoética, la ciudad constituye un aparato para la producción iconográfica imaginativa"17. De lo anterior da cuenta Yi fu Tuan al decir los sobrenombres [de una ciudad] complementarían los símbolos visuales: "de esta manera Florencia es el Domo o la Piazza della Signoria pero es también la Fiorente. New York es su famoso perfil del cielo pero también es la Empire City y muchas otras docenas de epítetos que compiten". ${ }^{18}$

Es probable que el cuestionamiento planteado a partir del sentido en la mayoría de las ciudades del país, haya sido generado precisamente por el periodo de angustia y extravío en el que se vive en ellas. Al menos esto parece haber encontrado Steger. et al $^{19}$ en un estudio acerca de la búsqueda del significado, "parece que la gente se sentiría estimulada a buscar el significado de su vida cuando su sentido se erosiona". El mismo Viktor Frankl, creador de la logoterapia, establece al respecto, "El hecho de que hoy la gente identifique de forma tan general la logoterapia con una psicoterapia orientada hacia el sentido es, sin duda, un síntoma de nuestro tiempo, del estado de "enfermedad" del espíritu de la época"20. Ese espíritu de la época, que

11 (Holzapfel, 2005)

12 (Holzapfel, 2005)

13 (Sternberg: 2000), (White: 1999) (Gehl: 2006)

14 (Rose: 1995)

15 (Gregory, et al: 2009)

16 Cuthbert (2006)

17 (Wunenburger, 2004:43 en Lorente et al: 2007)

18 (Yi fu Tuan 1974)

19 Steger. Et al (2008)

20 Viktor Frankl (2001). 
problematizó el sentido, es un cuestionamiento esencialmente del siglo XX, geográficamente situado en las esferas occidentales de la academia. "A cada concepción del mundo le corresponde una concepción del espacio y un sistema de representación o perspectiva"21. La primera y segunda guerra mundial contribuyeron, con la destrucción de importantes ciudades europeas, a tal preocupación. "Esta ronda de destrucción fue obviamente sin precedentes. El tanque tradicional y el ataque de artillería por parte de un ejército enemigo demolió las ciudades en cuestión de semanas: los bombardeos aéreos produjeron resultados similares en horas" (Kostof: 1992)

El movimiento moderno por otra parte con su limpieza funcional terminó por quitar el sentido a vivir en la ciudad. "Las bombas fueron simplemente facilitadoras de un proceso de convertir a Europa a un nuevo orden urbano" (Kostof: 1992). Posterior a esto es que los teóricos del diseño urbano, a partir de la década de los años sesenta, se cuestionan acerca de los valores de vivir en la ciudad moderna, criticando severamente al modernismo y acusándolo de golpear duramente a la vida urbana. Estos volverían a rescatar a urbanistas como Camilo Sitte y el historicismo comunitario (Schorske: 2011).

De acuerdo a ellos, existirían ciertos principios intelectuales a través de los cuales se puede reconocer, sostener y reconstituir la integralidad de los buenos lugares en la ciudad. En la opinión de Sternberg (2000) una teoría integradora del diseño urbano debe contemplar ciertos principios tales como;

1. Una buena forma, cuyos principios artísticos estén basados en la geometría de la percepción visual, la escala de cuerpo del paseante, y la continuidad de la experiencia del mismo. (Gehl: 2006)

2. La Legibilidad, otro aspecto importante en las cualidades sensuales de la ciudad o del Sentido de lugar, es "Una ciudad legible es una cuyas partes constituyentes son fácilmente identificables y son fácilmente agrupadas en un patrón general", Sternberg (2000).

3. Jane Jacobs (1992) por otro lado, ferviente defensora de ciudades densas, diversas y vitales entiende que promover la vida de la calle es esencial para una buena ciudad, es así que las calles vitales necesitan tener los más complejos y densos usos y que estos se apoyen mutuamente. De ésta manera se consigue la vitalidad urbana.

4. En reacción al modernismo que se centró en las formas de los edificios puros e impersonales, calles que eran poco más que conductoras del tráfico, y patrones urbanos copiados alrededor del mundo sin relación a la localidad y el contexto, (Roca: 2007), también denominados "no lugares" (Auge: 2004); una nueva generación de pensadores ha enfatizado la otra cara más integral de la ciudad: su capacidad para exhibir historia, tradición, naturaleza, nacionalidad, u otros temas que resaltan el significado y solidifican la identidad. Aldo Rossi (1999) es enfático al señalar que "la ciudad es por sí misma depositaria de la historia".

En síntesis un buen espacio público está bien definido, hay claridad en los bordes, tiene una identidad espacial que lo hace memorable, es decir un lugar que se recuerda cuando se ha dejado el mismo. (Radford: 2013). Claramente tiene un carácter, posee una atmósfera, donde la actividad en el lugar crea una energía distintiva, un ritmo, una vibración. La Habitabilidad por otro lado es la condición de Lugares positivos, son afirmadores de la vida, ellos no solo son seguros y saludables sino de fácil acceso. De ahí que la Conexión es un aspecto muy importante y esto se relaciona con que los buenos espacios públicos están conectados a la comunidad mayor, ofrecen conexiones visuales

21 (Roca: 2007) 
con el paisaje y la ciudad de más allá. Por último la Sensualidad; Involucra nuestro sentidos y nuestras emociones. Algunas de estas incluso pueden ser negativas.

5. El carácter Lúdico se define como un espacio que contribuye a crear nuevas imágenes y el Misterio, ambos elementos fundamentales, se relacionan con un espacio que se devela progresivamente. Todos los anteriores son considerados como elementos importantes en el espacio público. Siendo el misterio particularmente interesante ya que atañe directamente a la sorpresividad de la vida urbana. Sin encadenarse a la repetición permanente, el misterio se conecta con la actividad ocasional, evitando que las ciudades se vuelvan monótonas, pone de relieve la necesidad del estimulo (Gehl: 2006). Los anteriores atributos de un buen espacio público pueden ser encontrados de acuerdo a White (1999) en espacios de trayectorias, portales o lugares propiamente tal. Pergolis (2005) sin embargo menciona solo dos, plazas-parques y calles.

En conclusión la imagen de una ciudad no pertenece a la ciudad sino a sus habitantes, ya que es el modo como los ciudadanos la representan en su mente. Por eso, la imagen identifica a la ciudad, no por como es, sino por cómo es percibida. Lo anterior sugiere, de acuerdo a Pérgolis (2005), "la ciudad adquiere sentido cuando es capaz de satisfacer el deseo de sus habitantes".

\section{Metodología.}

Se dividió el Taller de Urbanismo, IV año de la Escuela de Arquitectura-UACH, en grupos integrados por tres estudiantes. A cada grupo se les pidió seleccionar un lugar, definido en la matriz como "lugares con sentido". La matriz además contemplaba categorías explicativas del sentido y técnicas analíticas. Dentro de la matriz también se les entrego un procedimiento para recopilar la información en la forma de nivel de percepción, instrumentos de medición y datos cuantitativos, cuando fuere necesario. El encargo consistió en desarrollar un proyecto que incorporase en el análisis del lugar una definición de espacio público ajustado a los atributos del espacio a intervenir. El proyecto debía al menos agregar un principio más de diseño urbano, que complementase la conformación del lugar.

\begin{tabular}{|c|c|c|c|c|c|c|}
\hline Categorías & técnicas analíticas & $\begin{array}{l}\text { Lugares con } \\
\text { sentido } \\
\text { ocasional }\end{array}$ & $\begin{array}{l}\text { Tipos de espacio } \\
\text { público: } \\
\text { Recorrido, portal, } \\
\text { lugar }\end{array}$ & $\begin{array}{l}\text { Nivel de } \\
\text { percepción }\end{array}$ & $\begin{array}{l}\text { Instrumentos } \\
\text { de medición }\end{array}$ & Datos cuantitativos \\
\hline $\begin{array}{l}\text { La ajenidad } \\
\text { que } \\
\text { subvierte el } \\
\text { orden }\end{array}$ & Misterio & $\begin{array}{l}\text { Costanera, Calle } \\
\text { esmeralda }\end{array}$ & & individual/interno & $\begin{array}{l}\text { Plantas/fotograf } \\
\text { ías }\end{array}$ & \\
\hline $\begin{array}{l}\text { Ergo la } \\
\text { organizació } \\
\mathrm{n}\end{array}$ & Legibilidad/vitalidad & $\begin{array}{l}\text { Río, plaza de la } \\
\text { republica, Coliseo, } \\
\text { mercado } \\
\text { municipal, Casino } \\
\text { Dreams }\end{array}$ & & $\begin{array}{l}\text { Individual/interno/ } \\
\text { grupal/externo }\end{array}$ & $\begin{array}{l}\text { Mapas/fotografí } \\
\text { as/ }\end{array}$ & $\begin{array}{l}\text { Número de personas a } \\
\text { determinada hora del } \\
\text { día }\end{array}$ \\
\hline $\begin{array}{l}\text { El Paisaje } \\
\text { que } \\
\text { identifica }\end{array}$ & $\begin{array}{l}\text { Conexión visual, } \\
\text { Ludicidad/Confort }\end{array}$ & $\begin{array}{l}\text { Parque Saval, } \\
\text { jardín Botánico }\end{array}$ & & individual/interno & $\begin{array}{l}\text { Mapas/ } \\
\text { esquemas }\end{array}$ & \\
\hline $\begin{array}{l}\text { La actividad } \\
\text { que satura } \\
\text { los espacios }\end{array}$ & Significado & $\begin{array}{l}\text { Torreón (Yerbas } \\
\text { Buenas) }\end{array}$ & & Individual/externo & $\begin{array}{l}\text { Relatos/archivo } \\
\mathrm{s}\end{array}$ & \\
\hline $\begin{array}{l}\text { La dinámica } \\
\text { que } \\
\text { interviene }\end{array}$ & vitalidad & $\begin{array}{l}\text { Los Robles (Isla } \\
\text { Teja), Campus } \\
\text { Cultural, Torreón } \\
\text { (Yerbas Buenas) }\end{array}$ & & Grupal/externo & $\begin{array}{l}\text { Número de } \\
\text { personas/comer } \\
\text { cio }\end{array}$ & $\begin{array}{l}\text { Número de personas a } \\
\text { determinada hora del } \\
\text { día }\end{array}$ \\
\hline $\begin{array}{l}\text { La } \\
\text { insinuación } \\
\text { que seduce } \\
\end{array}$ & Sensualidad & $\begin{array}{l}\text { Estación de } \\
\text { ferrocarril, Puente } \\
\text { cruces }\end{array}$ & & Individual/interno & $\begin{array}{l}\text { croquis/fotograf } \\
\text { ías }\end{array}$ & \\
\hline
\end{tabular}

Tabla 1 Matriz de análisis de los lugares

Fte. Elaboración propia 


\section{REVISTA DE \\ URBANISMO}

ISSN 0717-5051

http://revistaurbanismo.uchile.cl
Revista de Urbanismo No30 - Enero - Junio de 2014 Departamento de Urbanismo - FAU - Universidad de Chile

\section{Resultados.}

La propuesta N.1 Se localiza en el sector de General Lagos, área urbana de interés histórico y gran potencial de desarrollo, donde se identifican aspectos vinculados al significado histórico del espacio público (Figura 1).

Dentro de los atributos del lugar estaba el hecho de ser un barrio histórico con una clara legibilidad definida a través de las alturas, texturas de pavimentos, y de las tipologías arquitectónicas, consecuencia del legado de la colonización alemana del siglo XIX (Figura 2).

El proyecto busca integrar el Torreón, en la forma de un hito central de articulación de las actividades actuales, transformándose en un nodo principal de la calle General Lagos. La conexión del usuario con el río se facilita mediante la incorporación de actividades de servicios y ocio en la forma de cafés y gastronomía que estimulan la permanencia. Por otra parte la estrategia planteada busca revitalizar el lugar por medio de transformar el nodo principal propuesto en una plaza, a través de la prolongación de la textura existente del pavimento. De manera se disminuye la velocidad del automóvil y el trasporte público, dando un mayor protagonismo al peatón. Por último, se interviene la infraestructura al eliminar las veredas, creando un paseo peatonal continuo. (Figura 3). En síntesis con esta estrategia se persigue añadir vitalidad como principio de diseño urbano a los anteriores atributos propios del lugar.

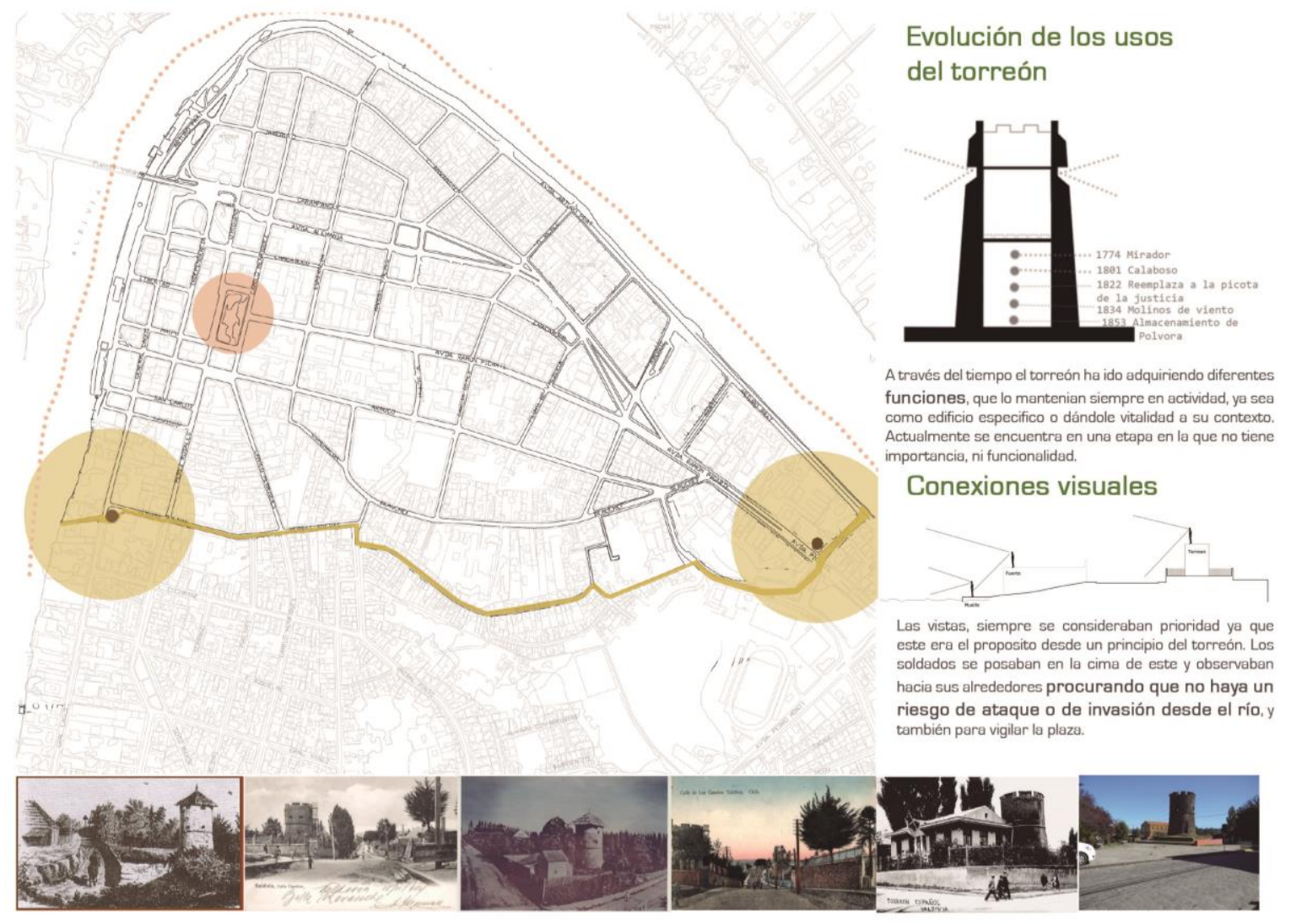

Fig. 1 El torreón Los Canelos, ubicación y evolución histórica en relación a sus usos. Fte. Elaboración propia 


\section{REVISTA DE}

\section{URBANISMO}

ISSN 0717-5051

Revista de Urbanismo N³0 - Enero - Junio de 2014

http://revistaurbanismo.uchile.cl Departamento de Urbanismo - FAU - Universidad de Chile
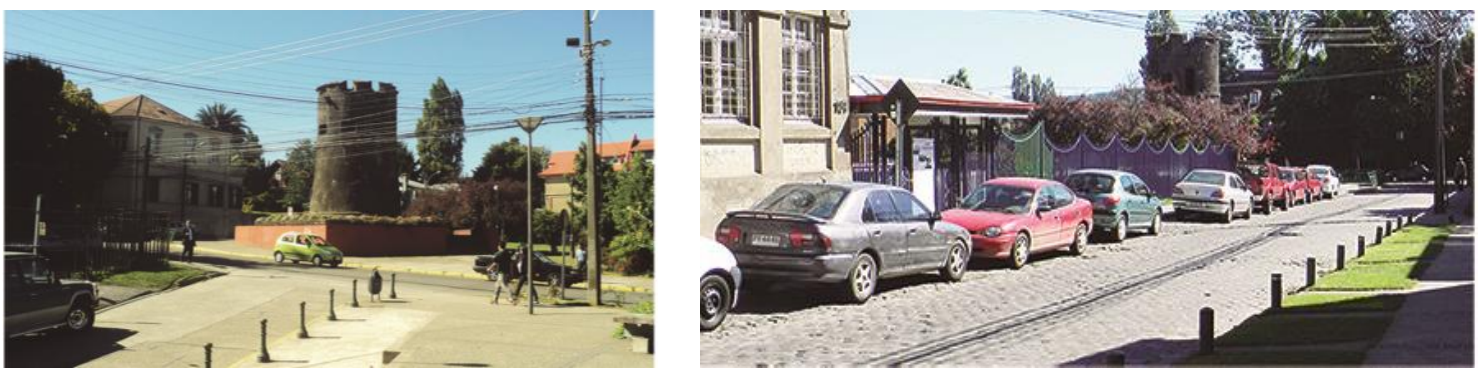

Fig. 2 El torreón El Canelo en la actualidad y los aspectos de legibilidad presentes en el lugar. Fte. Elaboración propia

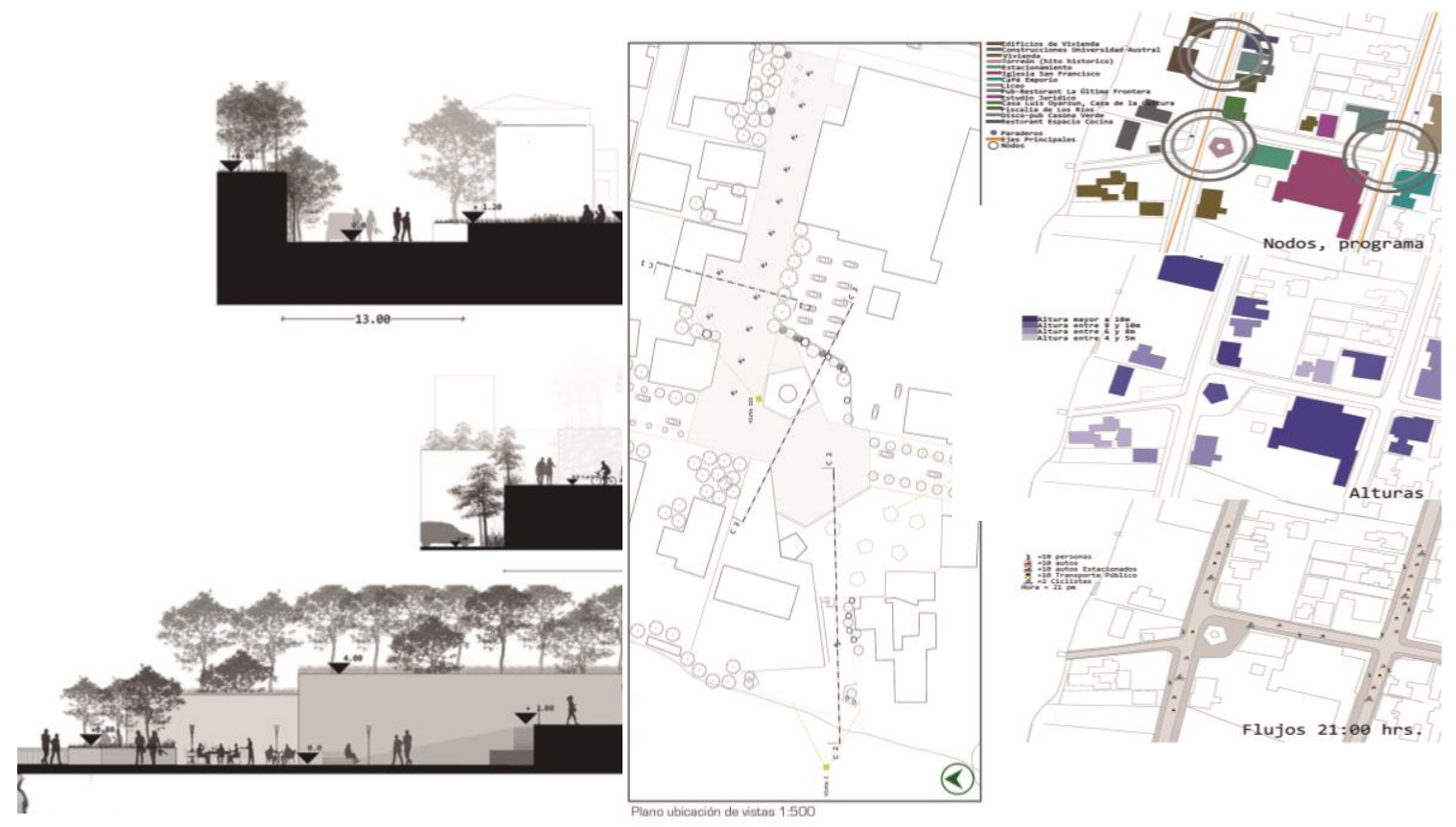

Fig. 3 Secciones de la propuesta y síntesis del funcionamiento espacial del lugar. Fte. Elaboración propia

Las variables de diseño aplicadas persiguen convertir la calle en un espacio peatonal que otorgue las condiciones físicas apropiadas para un mejor desempeño de las actividades actuales. Se potencia la legibilidad del lugar mediante la creación de espacios de permanencia, incorporando servicios, vías peatonales y mobiliario urbano como elementos centrales en la conexión hacia el río (Figura 4). 


\section{REVISTA DE \\ URBANISMO}

ISSN 0717-5051

http://revistaurbanismo.uchile.cl

Revista de Urbanismo N³0 - Enero - Junio de 2014 Departamento de Urbanismo - FAU - Universidad de Chile
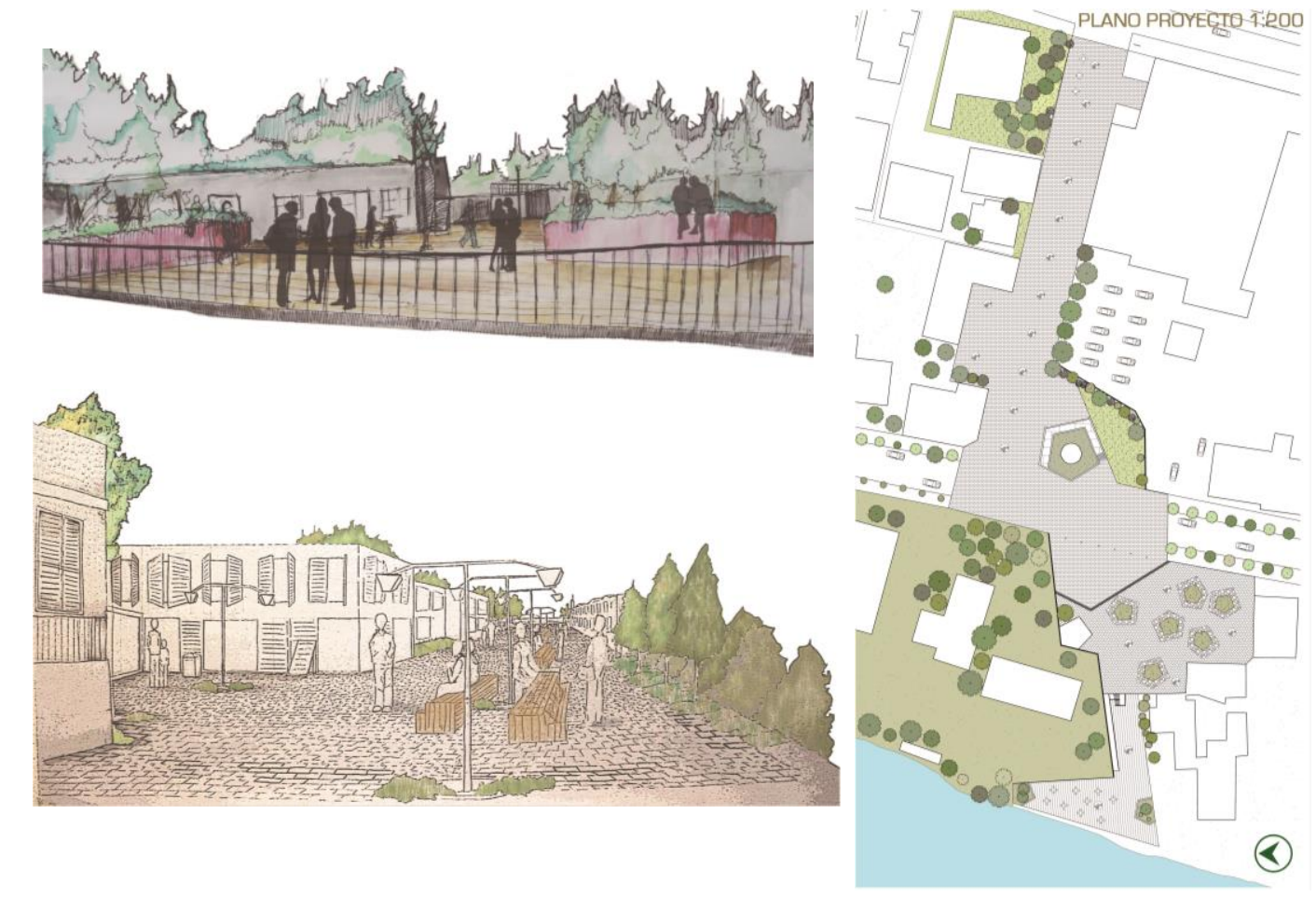

Fig. 4 Imágenes objetivo y planta de la propuesta

Fte. Elaboración propia

\section{Conclusiones}

El sentido es lo que sostiene la existencia, orienta al ser humano, evita que se sienta extraviado. De la misma manera, la ciudad al amparar la vida de miles de millones de seres humanos en el planeta, al establecerse un vínculo con ésta, puede ser una generadora de sentido. Mejores ciudades son ciudades que albergan múltiples lugares con sentido, sentidos que son persistentes en el tiempo, pero también sentidos que se renuevan, fortaleciendo el sentido de pertenencia de sus habitantes, quienes perciben en la conformación urbana una articulación profunda con su propia identidad colectiva cultural.

La aplicación de una teoría, puede resultar atractiva para poder entender el espacio, pero como se ha dejado en evidencia en este trabajo, también contiene las semillas para proyectarlo. La metodología permitió entender los principios de diseño urbano relevantes en la transformación del espacio público de la calle General Lagos. Principios como el significado y la legibilidad presentes y que actualmente se encuentran invisibilizados necesitan ser reactivados. Esta reactivación se logra por medio de otorgar permanencia en el lugar a través de elementos pequeños, intervenciones físicas mínimas que pueden aumentar el potencial de actividades del lugar. Con lo anterior se añade vitalidad, fortaleciendo el sentido del lugar. 


\section{Bibliografía}

CUTHBERT, A. 2006. The form of cities political economy and urban design. Australia: Blackwell Publishing.

GEHL. J. 2006. La humanización del espacio urbano. Barcelona: Editorial Reverté.

GREGORY, D. et al. 2009. The dictionary of human geography. London: Wiley-Blackwell.

HOLZAPFEL C. 2005. A la búsqueda del sentido. Santiago: Editorial Sudamericana.

INAM A. From Dichotomy to Dialectic: Practising Theory in Urban Design. Journal Of Urban Design May 2011; 16(2) pp. 257-277.

JACOBS, Jane. 1992. Muerte y vida de las grandes ciudades. Ediciones Península, Madrid.

KOSTOF, S. 1992. The city assembled. Boston: A Bulfinch press book.

LORENTE J., ANTOLIN J. \& FERNÁNDEZ J. 2007. "The Image of Urban Regeneration Concerning Bilbao: The City as Narrative and Experience". Revista Zer. 1, pp. 141- 166.

MÁRQUEZ, F. 2006. "Identidades urbanas en Santiago de Chile". En proposiciones Chile: identidad e identidades SUR, Corporación de Estudios Sociales y Educación,. pp. 84-98

MUNIZAGA, G. 1997. Diseño urbano teoría y método. Santiago: Ediciones Universidad Católica de Chile. PÉRGOLIS, J.C. 2005. La ciudad deseada, el deseo de la ciudad y su plaza. Buenos Aires: Nobuko.

PICON A. 2008. "Architecture and Public Space between Reassurance and Threat". Journal of Architectural Education, 61 (3). pp. 6-12.

RADFORD A. 1010. Urban design, ethics and responsive cohesion. Building Research \& Information. July; 38(4) pp. 379-389.

ROCA, M. 2007. Lugares urbanos y estrategias. Buenos Aires: Nobuko

RODRÍGUEZ, L. 2012. La ciudad como fuente icónica del sentido: las practicas discursivas al interior de la cultura geográfica en las ciudades de Buenos Aires, Santiago y Valdivia. tesis doctoral.

ROSE, G. 1995. "Place and identity: a sense of place". En Massey, D. and Jess. P. A place in the world?: places, cultures and globalization. New York: Oxford University Press Inc.

ROSSI, A. 1999. La arquitectura de la ciudad. Barcelona: Editorial Gustavo Gili, S.A.

SCHORSKE, C. 2011. La Viena de fin de siglo. Argentina: Siglo XXI editores.

STEGER M. TODD B. KASHDAN B. SULLIVAN A. and LORENTZ D. 2008. "Understanding the Search for Meaning in Life: Personality, Cognitive Style, and the Dynamic between Seeking and Experiencing Meaning". Journal of Personality 76(2) April, pp. 199-228

STERNBERG, E. 2000. "An integrative theory of urban design". Journal of the planning association. 66(3), pp. 265-278.

TALEN, E. "The Geospatial Dimension in Urban Design". Journal of Urban Design, Vol. 16. No. 1, 127-149, February 2011

TUAN, Y. 1974. Topophilia a study of environmental perception, attitudes, and values. New York: Columbia University Press.

WHITE, E. 1999. Path portal place appreciating public space in urban environments. Tallahassee: Architectural media Ltda. 